\title{
Effect of punishment: Facilitation or inhibition? A reply to Martin and Melvin
}

NELSON F, SMITH, JAMES R. MISANIN AND BYRON A. CAMPBELL

PRINCETON UNIVERSITY

Martin and Melvin take too narrow a definition of vicious circle behavior, restricting it to situations in which punishment is administered in the middle of a straight alley but not at the start or the goal. In the author's view, the paradigm should apply to any response motivated by aversive conditions and vicious circle behavior should occur whenever punishment-induced motivation generalizes to the conditions of training. It is further concluded that the experimental conditions leading to vicious circle behavior are not yet fully delineated.

This is a rebuttal to Martin \& Melvin's (1966) critique of our recent paper (Smith, Misanin, \& Campbell, 1966). Its aim is to substantiate our claim and to challenge a number of Martin and Melvin's conceptions of vicious circle behavior. While our paper was written with the view to attracting the reader's interest in the problem, it was not our intent to generate a controversy. The data were parametric, informative and non-controversial, but apparently our conclusion that punishment rarely facilitates performance during extinction of an avoidance response requires further defense.

Our first and perhaps major point concerns the definition of vicious circle behavior. Martin and Melvin state emphatically that our experimental procedure (punishment of an avoidance response in a shuttlebox) is not relevant to Mowrer's vicious circle hypothesis. Instead they say, "The vicious circle phenomenon is obtained in the following paradigm: After rats have learned to traverse a runway to avoid or escape shock, their responses are more persistent when a section of the runway, but not the start or goal box, is electrified than when it is not (Mowrer, 1960; Brown etal, 1964)." This, to us, is a narrow and constricted definition of vicious circle behavior which encompasses only a minute proportion of the phenomenon originally described by Mowrer. Martin and Melvin appear to have mistaken Mowrer's description of the specific experimental conditions producing vicious circle behavior in one experiment and the experimental conditions used in their own research for a general statement of the processes underlying vicious circle behavior. It seems clear from reading the whole of Mowrer's work that punishment of any response motivated by aversive conditions such as fear, anxiety, guilt, or pain may increase or perpetuate performance of the punished response. For example, he describes the effects of punishment of enuretic behavior as follows: "Many children have been so harshly dealt with in connection with toilet training that they live in real terror of nocturnal lapses; and once the disgracefulness of bed-wetting, as reflected by the attitudes of adults, is accepted by the child and 'internalized,' a kind of vicious circle is often set up, the enuresis creating further shame and apprehensiveness, which in turn may further aggravate the enuresis" (Mowrer, 1950, p. 398). And in another example he describes a hypothetical vicious circle experiment using rats and a barpressing response. In addition, Martin and Melvin cite Brown, Martin, and Morrow as proponents of this narrow point of view, but in a careful re-reading of that paper, we found no evidence that those authors in that paper intended to restrict vicious circle or selfpunitive behavior to punishment administered in the center portion of a straight alley. It thus seems obvious that the vicious circle paradigm is not limited to a straight alley with punishment administered somewhere in the center portion of the alley.

We also disagree with Martin and Melvin's analysis of behavior in the shuttlebox. They say that facilitation occurs only when punishment is administered in the middle of a response sequence, and that punishment is administered at the end of the response sequence in the shuttlebox. Observation of the animals in the shuttlebox does not confirm this view, since animals characteristically rush through the door of the shuttlebox, past the photocell beam to the end of the cage and often return to the original side of the cage from which they started. Thus, the response sequence continues after punishment is administered, and it is incorrect to say that the punishment is administered at the end of a response sequence in the shuttlebox. In an experiment bearing on this problem Kamin (1959) found no facilitative effects of punishment in a shuttlebox when Ss were required to cross back to the opposite compartment to escape punishment. Here punishment was clearly administered in the middle of a response sequence and yet punishment did not enhance behavior during extinction.

Next, we take umbrage at the criticism implied in the following comment: "While those studies are not methodologically identical to that of Smith et al, they seem as relevant as the lone empirical study of punishment cited by Smith et al." After all, our paper was published in Psychonomic Science, a non-archival journal, where it is hardly appropriate to compile extensive bibliographies, and the papers not cited in our bibliography were included in Church's (1963) bibliography, which was cited just for that purpose.

Next, Martin and Melvin indicate that our statement "...punishment is more likely to facilitate behavior 
when the experimental design makes it difficult for $\mathrm{S}$ to discriminate the conditions of punishment from those of avoidance training. .." is not correct. Instead, they point out that according to Mowrer vicious circle behavior occurs when "Ss cannot discriminate between the starting and shock areas of the runway." Here we must confess that our statement does contain elements of ambiguity. Our intent was to describe all vicious circle behavior as a failure of the $\mathrm{S}$ to discriminate the conditions of training from those of punishment on the assumption that generalization of punishment-induced fear to any of the cues associated with training reflects the failure of $\mathrm{S}$ to discriminate the training and punishment conditions. This, however, is not the discrimination hypothesis referred to by Mowrer, but it is the discrimination hypothesis referred to by Church (1963). To the extent that we included Mowrer (1960) and Solomon, Kamin, \& Wynne (1953) under the generic statement, we were in error. We did not, however, overlook the importance of the relative discriminability of the starting and shock areas of the apparatus in our introduction, since a major point was made of the relative difficulty of discriminating the start and punishment areas of the shuttlebox.

In a more general sense Martin and Melvin imply that whenever punishment is applied in the middle of a response sequence that vicious circle behavior occurs. Several studies demonstrate unambiguously that this mode of punishing is neither a necessary nor a sufficient condition for obtaining facilitation by punishment. Several investigators have administered punishment in the middle section following both escape and avoidance training and failed to find increased resistance to extinction. These include papers by Brown, Martin, \& Morrow (1964, Experiment 1); Seward \& Raskin (1960, Experiments 4 and 5); and Seward et al (1965). Examination of the experimental details of these studies does not lead (at least to us) to any obvious explanation as to why these investigators failed to find facilitation while those authors listed by Martin and Melvin found facilitation. Increased vigor of responding (but not increased resistance to extinction) during punishment is also found in the shuttlebox with dogs (Solomon, Kamin, \& Wynne, 1953; Brush, 1957), showing that punishment-induced facilitation can occur outside of the straight alley. We are not inclined to dismiss these important studies as simply "the interaction of intense shock with species (dogs)" as do Martin and Melvin. Instead we interpret these data as posing important problems for future research. Would punishment of the rat in the shuttlebox produce vicious circle behavior if just sub-tetanizing shocks were used and if the rat had to jump a barrier instead of passing through a swinging door?

Obviously vicious circle behavior does occur under some circumstances, but the necessary conditions for the occurrence or non-occurrence are not yet fully delineated. On this point it is now evident that at least some of the conditions listed by Brown, Martin, \& Morrow, e.g., that the intensity of the punishing stimulus be moderate, and the shift from training to punishment conditions be gradual, are not necessary conditions fol' the occurrence of vicious circle behavior. Martin \& Melvin (1964) obtained facilitation with abrupt transition from training to punishment conditions, and Martin reports that he found greater facilitation the higher the punishment level. On the positive side, we are convinced that punishment is more likely to produce vicious circle behavior when it is administered close to the start box in a straight alley, and we too have a paper in press (Campbell, Smith, \& Misanin) demonstrating this phenomenon with avoidance conditioning as do Melvin and Martin.

Finally, we interpret this state of affairs in which vicious circle behavior in the rat is found only (but not always) when punishment is administered in the center portion of a straight alley, preferably near the start box, as confirming our statement "facilitation of responding by punishment is the exception rather than the rule."

\section{References}

Brown, J. S., Martin, R. C., \& Morrow, M. W. Masochisticlike behavior in the rat. I. Facilitative effects of punishment on resistance to extinction. J. comp. physiol. Psychol., 1964, 57, 127133.

Brush, F. R. The effects of shock intensity on the acquisition and extinction of an avoidance response in dogs. J. comp. physiol. Psychol., 1957, 50, 547-552.

Campbell, B. A., Smith, N. F., \& Minsanin, J. R. The effects of punishment on extinction of an avoidance response: Avoidanceavoidance conflict or vicious circle behavior? J. comp. physiol. Psychol, in press.

Church, R. M. The varied effects of punishment on behavior. Psychol. Rev., 1963, 70, 369-402.

Kamin, L. J. The delay of punishment gradient. J. comp. physiol. Psychol., 1959, 52, 434-437.

Martin, R. C., \& Melvin, K. B. Vicious circle behavior as a function of delay of punishment. Psychon. Sci., 1964, 1, 415-416.

Martin, R. C., \& Melvin, K. B. Punishment-induced facilitation: Comments and analysis. Psychon. Sci., 1966, 5(7), 269-270.

Mowrer, O.H. Learning theory and personality dynamics. New York: York: The Ronald Press Co., 1950.

Mowrer, O.H. Learning theory and behavior. New York: Wiley, 1960.

Seward, J. P., King, R. M., Chow, T.', \& Shiflett, S. C. Persistence of punished escape responses. J. comp. physiol. Psychol., 1965, $60,265-268$.

Seward, J. P., \& Raskin, D. C. The role of fear in aversive behavior. J. comp. physiol. Psychol., 1960, 53, 328-335.

Smith, N. F., Misanin, J. R., \& Campbell, B. A. Effect of punishment on extinction of an avoidance response: facilitation or inhibition? Psychon. Sci., 1966, 4, 271-272.

Solomon, R. L., Kamin, L. J., \& Wynne, L. C. Traumatic avoidance learning: the outcomes of several extinction procedures with dogs. J. abnorm. soc. Psychol., 1953, 48, 291-302. 